\title{
Erratum zu: Edith Futscher, Heiko Kremer, Birge Krondorfer, Gerlinde Maurer (Hrsg.) (2014): Gerburg Treusch-Dieter. Ausgewählte Schriften 10.1007/s11614-014-0142-6
}

\section{Christine Goldberg}

(C) Springer Fachmedien Wiesbaden 2014

\section{Erratum zu: Österreich Z Soziol (2014) 39:253-255 \\ DOI: 10.1007/s11614-014-0142-6}

Richtigstellung:

In der Österreichischen Zeitschrift für Soziologie (ÖZS) ist im Heft 3/2014, S. $253-$ 255 die Rezension des Buches Edith Futscher, Heiko Kremer, Birge Krondorfer, Gerlinde Mauerer (Hrsg.) (2014): Gerburg Treusch-Dieter. Ausgewählte Schriften. Wien/Berlin: Turia + Kant erschienen. In der Rezension ist insofern ein Fehler enthalten, als der Name der Mitherausgeberin Gerlinde Mauerer irrtümlich als Gerlinde Maurer angegeben wird, sowohl bei der Angabe des Buchtitels als auch in der Kopfzeile und im Text der Rezension auf S. 255. Der richtige Name der Herausgeberin lautet Gerlinde Mauerer.

Für die Redaktion: Franz Ofner

Die Onlineversion des Originalbeitrages ist erreichbar unter doi: http://dx.doi.org/10.1007/s11614-014-0142-6

C. Goldberg $(\bowtie)$

Institut für Soziologie, Universität Wien,

Rooseveltplatz 2,

1090 Wien, Österreich

E-Mail: christine.goldberg@univie.ac.at 